\title{
Queer Children as Survivors of Child Sexual Abuse
}

\author{
Pragya Lodha \\ Clinical Psychologist, Mumbai. \\ Corresponding Author : Pragya Lodha \\ E-mail: pragya6lodha@gmail.com
}

Sexual violence is a pervasive phenomenon, affecting every culture and society, across demographics. Sexual violence may take various forms and encompasses sexual abuse, sexual assault, rape and other sexual crimes. Apart from the gruesome nature of assault, it is disappointing to note that the society's stigmatised approach to assault further only disempowers the victim. The victim is not just subject to the assault but is also discriminated and blamed for having 'called upon' the nature of act. What is to be remembered is that irrespective, it is never the victim's fault.

Under sexual violence and sexual crimes, childhood sexual abuse (CSA) is treated as one of today's most serious public health problems. The prevalence of CSA among lesbian, gay, bisexual and transgender (LGBT) individuals is noted to be substantially higher than it is in heterosexual populations. Children of sexual minority are on an average 4 times more likely to experience sexual abuse than heterosexual children. There are several reasons to this consequence and can be enlisted as:

- Prevalence of homophobia that regards these individuals (and the community) as an outcast and therefore they are deferred from just treatment in all spheres of life which increases the risk of sexual assault and violence

- The LGBTQ+ community is a minority one, faces higher rates of poverty and is stigmatised- these factors put the community at a greater risk for abuse and assault.

- Culturally, it is believed that having the LGBT youth subject to rape or forced sexual engagement with the opposite will help 'transform' them to becoming straight which is nothing but ridiculous.

- Among the community, transgender and bisexual women are further more prone to experience sexual violence and assault- as many as half of them do face sexual assault at some point in their lifetime.

- Non-acceptance by family and family members predisposes to the child for greater homelessness and this further increases the risk for sexual violence being experienced. It is a known fact that many children identifying their gender identity and / or sexual orientation as LGBTQ+ have either been outcast from the home or the home environment has led them to run away from their homes

- For various transgender persons, prostitution is a means of living and the nature of profession (along with lack of awareness and resources for better health care) increases the risk for sexual violence for them.

- The way society hypersexualizes LGBTQ people and stigmatizes our relationships can lead to unstable and unhealthy interpersonal relationships. Often, it also leads to intimate partner violence which stems from internalized homophobia and shame.

When we speak of sexual violence among queer children, two important points that need addressal are:

1. In most instances (90\%-95\%), children are abused by someone they know and trust, typically a male who may either be heterosexual or gay man. The perception that most perpetrators are gay men is a myth and harmful stereotype. 
2. Often children develop the belief that their homosexual identity and /or orientation is a consequence of the sexual abuse by the opposite gender which makes them feel sexually revulsed. However, this is not true. There may be fear, anger or disgust to the gender that were the perpetrator; it may cause confusion about the identification with gender but abuse does nothing to transform heterosexual orientation to a homosexual one.

It is a well-documented fact that CSA has wide-ranging and long-lasting negative impact on victims' physical health as well as mental health. to understand this impact better- CSA can lead to children and adolescents have an increased rate of risky sexual behaviours, increased risk for HIV and other sexually transmitted infections, depression, suicidal ideation, post-traumatic stress disorder and substance abuse. These children are at an increased risk for future victimization, impaired adult functioning and altered attitudes about self, others and the world. Developmentally, the incidence of child sexual abuse translates to trauma in adulthood which may further predisposes them to severe mental illnesses. The burden of mental health needs greater attention because individuals tend to seek immediate help or physical health problems but mental health issues are often delayed or ignored yet because of the stigma attached.

Another observation that possibly contributes to mental health issues among LGBTQ+ persons is the disclosure of the age of coming out. Notedly, the age of coming out has decreased over years. In the 1970s and 1980s, the age of coming out was a mean of 22 years old and that after 2015 has come down to 14 years (on an average). Despite the recent celebrated fact of decriminalisation of their identities of being LGBTQ+ in India which fosters for the freedom of expression and despite the dramatic changes in increased support towards the community, mental health problems continue to be a rising concern. The explanation to this briefly is that younger children (14 years) have fewer cognitive resources to deal with the stigmatisation and discrimination they face from society as compared to the elder ones (22 years).

The layers of stigma are multiple when it comes to understanding the mental health impact of queer children and who have faced sexual violence. Here are some interventions to address the same:

1. To begin with, addressing homophobia and talking about the awareness of the LGBTQ+ spectrum is the first layer of stigma that needs attention so that the child can be accepted for who he or she is. This fosters better interpersonal relationships and fulfils the need for security for the growing child.

2. An emotionally secure relationship between the parent and the child creates the space for trust where the child can come and share whatever he or she wants to. It is important for a child to develop secure relationships with the parents as they are the backbone of social support for the child.

3. Parents should help the child figure out events that he/she can control from those that are uncontrollable. Additionally, parents can encourage their child to talk positively about themselves. It is essential to reward you child as much as is to correct them for mistakes.

4. Don't hesitate to take your child to a mental health professional- it is good not to avoid the consequences and take immediate help to prevent further suffering.

5. Use a kind but firm approach to let your child know if their behaviour is unacceptable. Let your child know that their emotions are normal, but encourage your child to express his or her anger in appropriate ways.

6. School-based educational programs about CSA concepts, self-protection, and directions to tell a trusted adult if approached or abused have been effective in increasing children's knowledge about CSA and about self-protection. Research has found reduced propensity of risk to sexual abuse when females were educated about sexual abuse at schools

7. Home visiting programs and family services that strengthen and support mothers have the potential to reduce all forms of child maltreatment, including CSA

8. Arrange for positive and engaging activities for the child so they may have something more productive to focus their energies on. 
9. Parental monitoring of Internet website access by children and adolescents has now become an essential part of CSA prevention

10. Preventing sexual violence and taking care of a child's mental health requires a joint effort at interpersonal, societal and governmental level. In addition, important to let children have their own identities in terms of gender identity or sexual orientation. It is a part of normal development and important for their well-being, self-esteem and self-confidence. Let's do our own bits to allow our children to believe in, grow in healthier and happier spaces.

Apart from this, what mental health professionals must keep in mind:

1. Sometimes the therapist may not be comfortable dealing with cases of sexual abuse (including CSA), in that case it is best to refer to trauma therapists or those professionals who are comfortable dealing with such cases. At times, the surprise or shock emotion can disturb the patient (they may also feel judged or further victimised or as if it were their fault) which the therapist may not be aware of.

2. Maintaining confidentiality is extremely important as the patient may not be ready to disclose the information. Sometimes, adults may not want to report it or let their parents / family know then, professionals must respect that and work with the patient's needs at that moment.

3. In case of children, it is a must that therapists must be aware of POCSO and take the necessary action of reporting.

4. Therapists may have to be extra sensitive to the need of the patient who report sexual abuse and cater to what is most important to the patient in that period of time.

5. There are several therapeutic modalities that can be used with children/ adults with complaints of sexual abuse, one must be appropriately trained in them in order to practice as dealing with such sensitive cases requires for the therapist to know when to and how to deal with the trauma.

6. Sometimes children may not feel comfortable talking about the traumatic incident, it is important to maintain a patient stance and not force them to talk.

7. Very important is that children be conveyed that it was not their fault and they must not feel guilty for the act of abuse.

8. Many a times, adults come to therapy and talk about their experience of child sexual abuse which went unaddressed, it is very important for therapists to address it with equal sensitivity and care. Experience of trauma whether old or new, takes a great toll on an individual's mental health and must be addressed appropriately.

9. The care for children who identify as queer is double fold since the stigma also is double fold due to the homophobic nature of the society.

10. Therapists not comfortable with the LGBTQ+ population may refer to genderaffirmative therapists. and the ones unaware must educate themselves about their issues.

11. Queer children may feel more affected by trauma and often confuse their orientation as a result of the trauma experienced. Therapists must help them understand and believe in the reality of difference.

12. Therapists must also use their potency to understand how and when to speak about the queer child's identity to his / her parents / family.

Remember: It is not the child's fault. Do not react in anger towards the child if they report about their incident of abuse. Do not blame them or make them feel guilty about it. It is NEVER their fault. Let children know that many emotions like sadness, guilt, loneliness, fear, pain and isolationare normal responses to traumatic experiences.

\section{REFERENCES \& RECOMMENDED READING}

1. Gibson L, Leitenberg H. Child sexual abuse prevention programs: Do they decrease the occurrence of child abuse?. Child Abuse Negl 2000;24:1115-25. 
2. Hanson RF, Self-Brown W, Fricker-Elhai A, Kilpatrick DG, Saunders BE, Resnick HS. The relationship between family environment and violence exposure among youth: Findings from the National Survey of Adolescents. Child Maltreat 2006;11:3-15.

3. MacLeod J, Nelson G. Programs for the promotion of family wellness and the prevention of child maltreatment: A meta-analysis. Child Abuse Negl 2000;24:1127-50.

4. Olafson E, Boat B. Long-term management of the sexually abused child: Considerations and challenges". In Treatment of child Abuse: Common ground for mental health, medical, and legal practitioners, Edited by: Reece, R. M. 14-35. Baltimore, MD \& London, England: Johns Hopkins University Press; 2000.

\section{Acknowledgements - Nil \\ Source of Funding - Nil \\ Conflict of Interest - Nil}

